\title{
Magnesium-based composites with improved in vitro surface biocompatibility
}

\author{
Zhiguang Huan $\cdot$ Jie Zhou $\cdot$ Jurek Duszczyk
}

Received: 4 May 2010/Accepted: 21 September 2010/Published online: 5 October 2010

(c) The Author(s) 2010. This article is published with open access at Springerlink.com

\begin{abstract}
In this study, bioactive glass (BG, 45S5) particles were added to a biodegradable magnesium alloy (ZK30) through a semi-solid high-pressure casting process in order to improve the surface biocompatibility of the biomaterial and potentially its bioactivity. The observation of the as-cast microstructures of ZK30-BG composites indicated homogeneous dispersion of BG particles in the matrix. SEM, EDX and EPMA showed the retention of the morphological characteristics and composition of BG particles in the as-cast composite materials. In vitro tests in a cell culture medium confirmed that the composites indeed possessed an enhanced ability to induce the deposition of a bone-like apatite layer on the surface, indicating an improved surface biocompatibility as compared with the matrix alloy.
\end{abstract}

\section{Introduction}

In recent years, magnesium alloys have attracted much attention as potential biodegradable bone implant materials due to their biodegradability in the bioenvironment as well as their favourable mechanical properties, especially the elastic modulus being close to that of the bone which will effectively decrease the stress shielding effect $[1,2]$. Many studies have been conducted on magnesium and its alloys for orthopaedic implants. Most of these studies are focused on the ways to improve corrosion resistance in physiological media, for example, through alloying [3] or coating [4].

Z. Huan $\cdot$ J. Zhou $(\bowtie) \cdot$ J. Duszczyk

Department of Materials Science and Engineering,

Delft University of Technology, Mekelweg 2,

2628 CD Delft, The Netherlands

e-mail: j.zhou@tudelft.nl
Quite encouraging results have been obtained. Further in vitro and in vivo tests will provide essential data for further material and process optimization before the pre-clinical test stage is reached.

Another issue of these potential biomedical materials, being as important as corrosion resistance but not always addressed, concerns their bioactivity, i.e. the ability of the implant to form bonding with the surrounding bone tissue after implantation. While a number of in vivo studies have shown good bone attachment to magnesium implants after 9 to 18 week implantation and good biocompatibility of magnesium in long-term service [5, 6], some other research on the early bone response to magnesium bone implants has led to inconsistent results. For example, only $50 \%$ of magnesium implants were fixed at 5 weeks post-implantation [7]. In some cases, gaps could still be observed between the implant and bone tissue after 14-week implantation [6], even though the material showed a moderate degradation rate. It is clear that efforts are needed to improve the surface biocompatibility and bioactivity of $\mathrm{Mg}$-based materials and speed up the early tissue response to the implant [8].

Introducing bioactive particles that have good ability to induce the deposition of $\mathrm{Ca}-\mathrm{P}$ compounds from simulated body fluid into a metal matrix to form a metal matrix composite may be an effective way to elevate the surface biocompatibility and bioactivity of the matrix material, as demonstrated in a recent study [9]. Ning and Zhou [10] reported that a Ti/hydroxyapatite (HA) biocomposite (with a Ti/HA ratio of $1: 1$ by volume) indeed had the ability to induce apatite nucleation and growth on its surface in simulated body fluid. Witte et al. [11] designed a composite with AZ91D as the matrix and HA particles as reinforcement. Their results showed that the composite with $20 \%$ HA by weight was a cytocompatible biomaterial and the distribution and size of HA particles were of major 
importance for mechanical and corrosive properties. It is however known that HA has a minimal degradability and its bioactivity still needs to be improved [12].

A previous study demonstrated a moderate degradation rate and good cytocompatibility of ZK30 ( $3 \mathrm{wt} \% \mathrm{Zn}, 0.6$ wt $\% \mathrm{Zr}$ and balance $\mathrm{Mg}$ ) [13] that contained no potentially toxic elements such as aluminium in AZ91. The present study was aimed at exploring the feasibility of using commonly acknowledged bioactive and biodegradable glass (BG, 45S5) as the reinforcing phase in the composites with the ZK30 magnesium alloy as the matrix and confirming the surface biocompatibility of the composites. The structures of the composites, including the distribution of bioactive particles in the matrix as well as their mechanical properties were investigated. The surface biocompatibility of the composites was evaluated by characterizing the corrosion layer on samples soaked in a cell culture medium and comparing it with that of the matrix sample.

\section{Experimental}

\subsection{Material preparation}

ZK30-BG composites were prepared by a semi-solid, high pressure casting method. The ZK30 alloy was heated to $635^{\circ} \mathrm{C}$ to reach a semi-solid state. $45 \mathrm{~S} 5$ bioglass particles with a composition of $45 \% \mathrm{SiO}_{2}, 24.5 \% \mathrm{Na}_{2} \mathrm{O}, 24.5 \% \mathrm{CaO}$ and $6 \% \mathrm{P}_{2} \mathrm{O}_{5}$ by weight were introduced. Upon stirring, the mixture was cast into a cylindrical form by using a high pressure casting machine. The bioglass powder had a median size of $40 \mu \mathrm{m}$. The volume fractions of BG particles in the composites were 3.4, 6.9 and $14.3 \%$, corresponding to 5,10 and $20 \%$ by weight, respectively.

\subsection{Observation of microstructure and determination} of mechanical properties

Samples for microstructure observation were cut from the ingots, ground by $\mathrm{SiC}$ papers up to 2000 grit, and then polished down to $1 \mu \mathrm{m}$. A Leica optical microscope and a scanning electron microscope (SEM, JSM-6500F, JEOL) combined with an energy dispersive X-ray (EDX) spectrometer (INCA Energy, Oxford Instruments) were used.
Furthermore, a JEOL JXA 8900R electron probe microanalyzer (EPMA) was used to determine the distribution of the silicon element in the composites. The acceleration voltage was set at $15 \mathrm{keV}$ and the probe current at $100 \mathrm{nA}$ using a focused electron beam. The size of the analysis area was $100 \times 100 \mu \mathrm{m}^{2}$ with a step size of $1.0 \mu \mathrm{m}$.

For compressive testing, specimens with a length of $15 \mathrm{~mm}$ and a diameter of $10 \mathrm{~mm}$ were machined in accordance with DIN EN 50106. Tests were performed at a crosshead speed of $1 \mathrm{~mm} / \mathrm{min}$. Three repeat tests were performed for each material.

\subsection{Immersion test}

The immersion test was conducted by soaking samples in the cell culture medium (minimum essential medium with Earle's balanced salts, SAFC Bioscience Inc., USA). The minimum essential medium with Earle's balanced salts (E-MEM) was selected, because it represents the ion concentrations of blood plasma and contains some kinds of amino acid that is also present in human plasma [14]. The concentrations of ions in E-MEM in comparison with those in the human blood are listed in Table 1. The as-fabricated composites as well as the ZK30 alloy were cut into disks with a diameter of $10 \mathrm{~mm}$ and a thickness of $2 \mathrm{~mm}$. The surfaces of the samples were ground by $\mathrm{SiC}$ papers up to 2000 grit, polished down to $1 \mu \mathrm{m}$ and dried, before they soaked in E-MEM. A disk was immersed in the E-MEM solution with a volume of $22 \mathrm{ml}$ at $37.0^{\circ} \mathrm{C}$, thus the ratio of the volume of the solution to the apparent surface area of the disk being $0.1 \mathrm{~cm}^{-1}$ [15].

After soaking in the cell culture medium for $24 \mathrm{~h}$, the samples were taken out and dried. Structural changes were examined using SEM combined with EDX.

\section{Results and discussion}

Figure 1 shows the microstructures of the ZK30-BG composites with different volume fractions of BG particles. As can be seen, black particles are homogeneously dispersed in the matrix and the number density of the black particles indeed increases with increasing volume fraction of BG particles as desired (Fig. 1a, c, e). SEM revealed that

Table 1 Ion concentrations in human blood and E-MEM [13]

\begin{tabular}{lllllllllll}
\hline & $\begin{array}{l}\mathrm{Na}^{+} \\
(\mathrm{mmol} / \mathrm{l})\end{array}$ & $\begin{array}{l}\mathrm{K}^{+} \\
(\mathrm{mmol} / \mathrm{l})\end{array}$ & $\begin{array}{l}\mathrm{Ca}^{2+} \\
(\mathrm{mmol} / \mathrm{l})\end{array}$ & $\begin{array}{l}\mathrm{Mg}^{2+} \\
(\mathrm{mmol} / \mathrm{l})\end{array}$ & $\begin{array}{l}\mathrm{C}^{1-} \\
(\mathrm{mmol} / \mathrm{l})\end{array}$ & $\begin{array}{l}\mathrm{HCO}_{3}{ }^{-} \\
(\mathrm{mmol} / \mathrm{l})\end{array}$ & $\begin{array}{l}\mathrm{HPO}_{4}{ }^{2-} \\
(\mathrm{mmol} / \mathrm{l})\end{array}$ & $\begin{array}{l}\mathrm{SO}_{4}{ }^{2-} \\
(\mathrm{mmol} / \mathrm{l})\end{array}$ & $\begin{array}{l}\mathrm{Amino} \mathrm{acids} \\
(\mathrm{mg} / \mathrm{l})\end{array}$ & $\begin{array}{l}\mathrm{Dex} / \mathrm{Glu}^{2} \\
(\mathrm{~g} / \mathrm{l})\end{array}$ \\
\hline Blood plasma & 142 & 5.0 & 2.5 & 1.5 & 103 & 27 & 1.0 & 0.5 & $\mathrm{ND}$ \\
E-MEM & 151 & 5.37 & 1.80 & 0.811 & 125 & 26.2 & 0.897 & 0.811 & 0.0860 & 1 \\
\hline
\end{tabular}

$N D$ not determined 

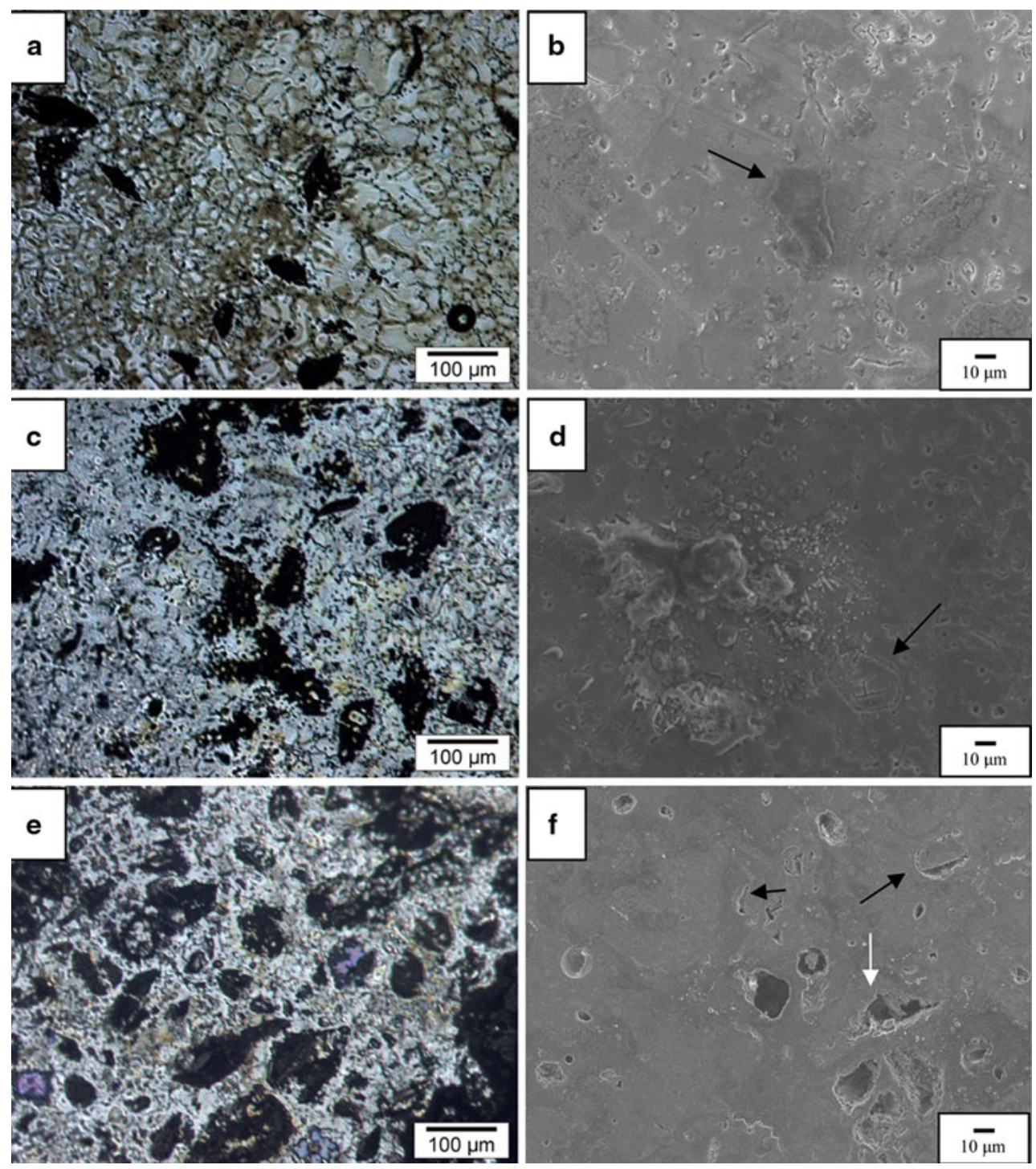

Fig. 1 Surface morphologies of the ZK30-BG composites with $3.4 \%$ (a, b), $6.9 \%(\mathbf{c}, \mathbf{d})$ and $14.3 \%(\mathbf{e}, \mathbf{f})$ BG particles by volume under optical microscope (a, c, e) and SEM (b, d, f). The black arrows point

the black particles had angular shapes, as those of the initial BG powder particles, suggesting little reaction took place during material preparation. In addition, SEM showed some more details of the microstructures of the composites. The composites with 3.4 and $6.9 \%$ BG by volume were slightly porous and most of the pores had sizes below $10 \mu \mathrm{m}$ (Fig. 1b, d). The difference in porosity between these two composites was not distinct. However, in the composite with $14.3 \%$ BG particles by volume, the pore sizes were considerably larger (Fig. 1f). In a composite ingot made by the semi-solid casting method, in general, porosity may arise from (i) gas entrapment during mixing, (ii) hydrogen evolution, and (iii) shrinkage during solidification [16]. For the present composites, the porosity might result from gas bubbles entering the slurry either at the reinforcing particles, while the white ones point at the pores in the composites

independently or as gas envelopes of the reinforcing particles. Indeed, it was observed that the porosity in stir-cast composites increased almost linearly with particle content [16]. Such an increase in porosity will have an adverse effect on the mechanical strength of the composite. As shown in Fig. 2, the compressive strength of the composite indeed decreased from 330 to $240 \mathrm{MPa}$ as the volume fraction of $\mathrm{BG}$ particles increased from 0 to $14.3 \%$. It is however important to note that the strengths of the composites are still considerably higher than the typical strength of human cortical bone (88.3-163.8 MPa) [17] and therefore the sacrifice in strength due to the BG particles and associated porosity is not a matter of serious concern. The effect of the porosity may be more on the degradation rate than on the compressive strength and, 


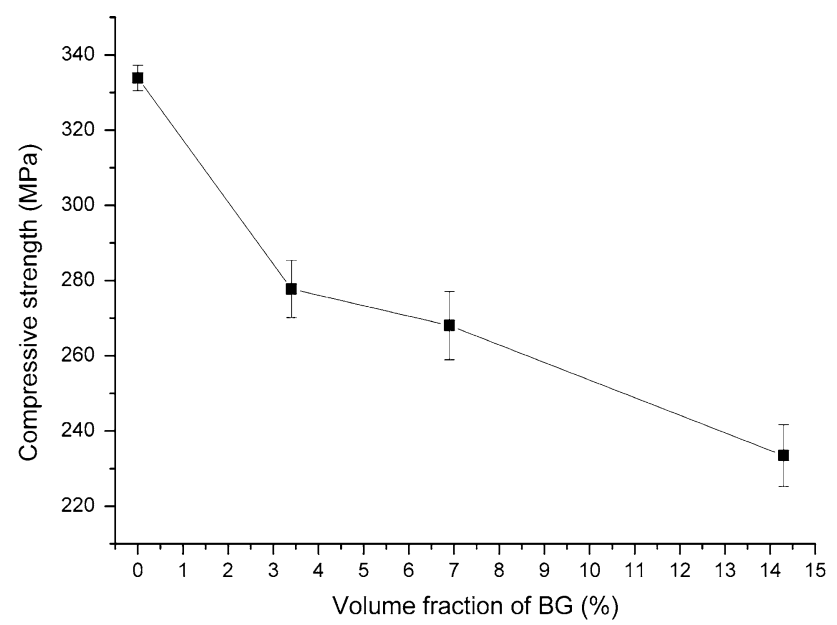

Fig. 2 Compressive strengths of the ZK30-BG composites with different volume fractions of BG particles

therefore, it is necessary to take measures to eliminate the residual pores in the structure. Vacuum hot pressing, hot isostatic pressing and especially hot extrusion involving strong shearing have been proven to be effective methods capable of consolidating initially porous materials.

Since the biomedical property of a bioactive ceramic material is closely related to its chemical composition, it is of utmost importance to keep the compositional characteristics of BG particles in the composite unchanged [18]. In general, it is rather difficult to ascertain the retention of the chemical composition of BG particles due to their amorphous structure. In the present study, EDX analysis was performed to confirm the compositional retention of BG particles in the composites. As can be seen from Fig. 3a, only $\mathrm{Mg}, \mathrm{Zn}$ and a small amount of element $\mathrm{O}$ were detected by EDX, and the mass ratio of $\mathrm{Mg}$ and $\mathrm{Zn}$ was close to that of the designed ZK30 composition, which means that the matrix composition was well preserved after the casting procedure. As to the BG particles in the composites, EDX analysis revealed the presence of $\mathrm{Ca}, \mathrm{Si}, \mathrm{Na}$, $\mathrm{O}$ and a small amount of $\mathrm{Mg}$ (Fig. 3b). The presence of $\mathrm{Mg}$ could be attributed to the magnesium surrounding the BG particles or to mild reactions at the interfaces between the matrix and BG particles. For a clearer comparison, the weight percents of $\mathrm{Ca}, \mathrm{Si}, \mathrm{Na}$ and $\mathrm{O}$ of the analyzed particles as determined by EDX are listed in Table 2 and compared with those of the theoretical elemental composition of BG particles. It can be seen that the discrepancies between the as-measured and theoretical composition data were not marked, suggesting the retention of BG particles in the composites. It is of particular importance to note the high Si concentration in the BG particles, which is necessary for the excellent bioactivity of a bioactive glass [18]. EPMA analysis indeed revealed the silicon element with enhanced intensities scattered all over the matrix, which corresponded to the locations of BG particles (Fig. 4). It was thus clear that the basic chemical composition of BG particles remained largely intact during semi-solid high pressure casting, which would be essential for the preservation of their bioactivity. In other words, semi-solid high pressure casting appeared to be a viable method to fabricate ZK30-BG composites.
Fig. 3 EDX analysis of the matrix (a) and particles (b) in the ZK30-BG composites

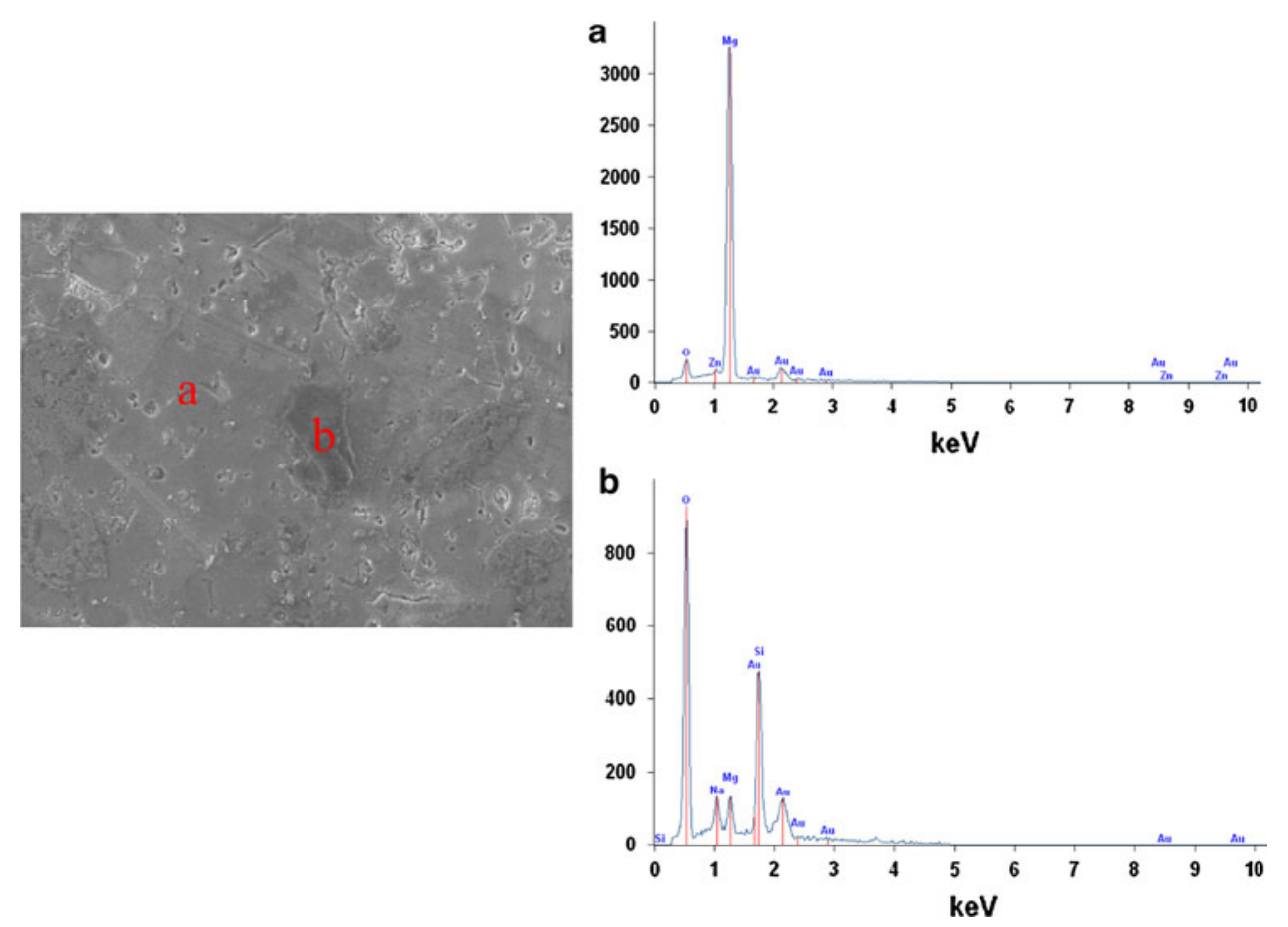


Table 2 EDX determined composition of BG particles in the composites in comparison with the designed composition of BG (wt \%)

\begin{tabular}{llllll}
\hline & $\mathrm{Ca}$ & $\mathrm{Si}$ & $\mathrm{Na}$ & $\mathrm{O}$ & $\mathrm{Mg}$ \\
\hline As-designed & 17.5 & 21.0 & 18.2 & 40.7 & 0 \\
As-measured & 22.3 & 29.7 & 14.2 & 30.6 & 3.2 \\
\hline
\end{tabular}

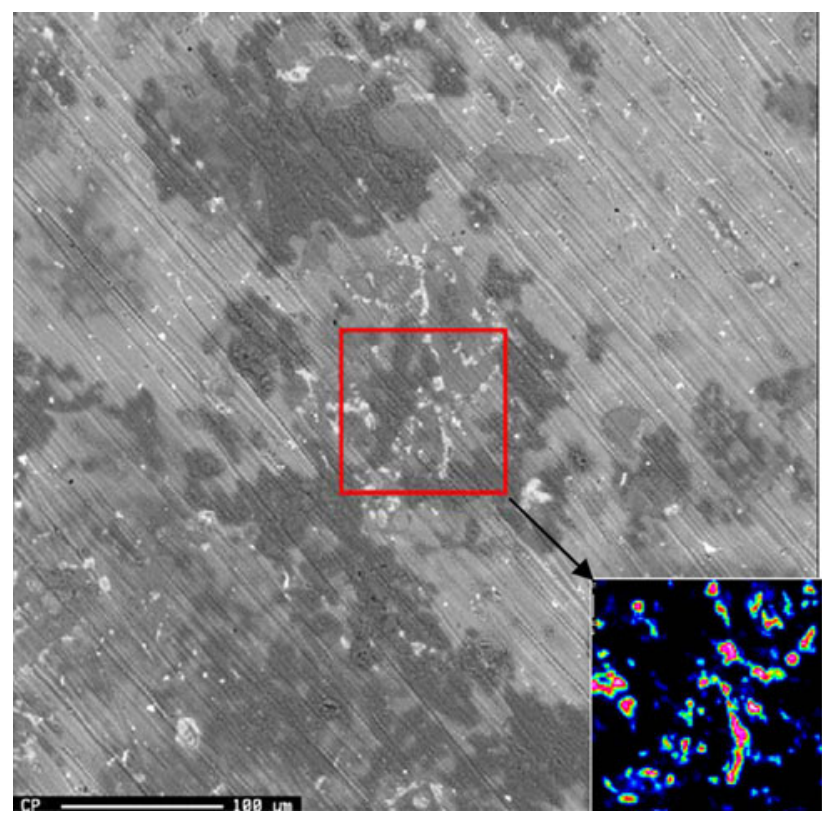

Fig. 4 Distribution of $\mathrm{Si}$ in the composite as determined by EPMA. The analysis area on a ZK30-BG MMC sample is indicated by the square in the Backscattered Electron Image (BEI). The intensity of the $\mathrm{Si} \mathrm{K} \alpha$ in the framed area is represented by the gray scale (or a jetlike colour scheme in the online version). Here black represents a low signal and light gray-white higher intensity signals (pinkish-white the highest intensity in the online version)

The surface morphologies of the composites after immersion in E-MEM for $24 \mathrm{~h}$ are shown in Fig. 5. During immersion, pitting corrosion indeed occurred on the surface of the ZK30 alloy sample without BG reinforcement (Fig. 5a). In contrast, a deposition layer was formed on the surface of the composite samples, and the area of this layer increased with increasing volume fraction of $\mathrm{BG}$ particles in the composite (Fig. 5b, d). EDX analysis of the surface layer showed increases in the $\mathrm{Ca}$ atomic percent and $\mathrm{Ca} / \mathrm{P}$ molar ratio, as the volume fraction of $\mathrm{BG}$ particles increased from 0 to $14.3 \%$ (Fig. 6). The $\mathrm{Ca} / \mathrm{P}$ ratios of the composites in the range of 1.2-1.35, being lower than the theoretical value (1.67), show that the newly formed apatite layer is a Ca-deficient apatite layer, consistent with the properties of bone-like apatite formed on an HA-bioglass composite [19] and on bioglass [20]. The results indicated that the BG particles present in the composite were indeed able to induce faster and more homogeneous deposition of a Ca- and P-rich layer on the magnesium alloy matrix. The operating mechanism of spontaneous apatite formation on
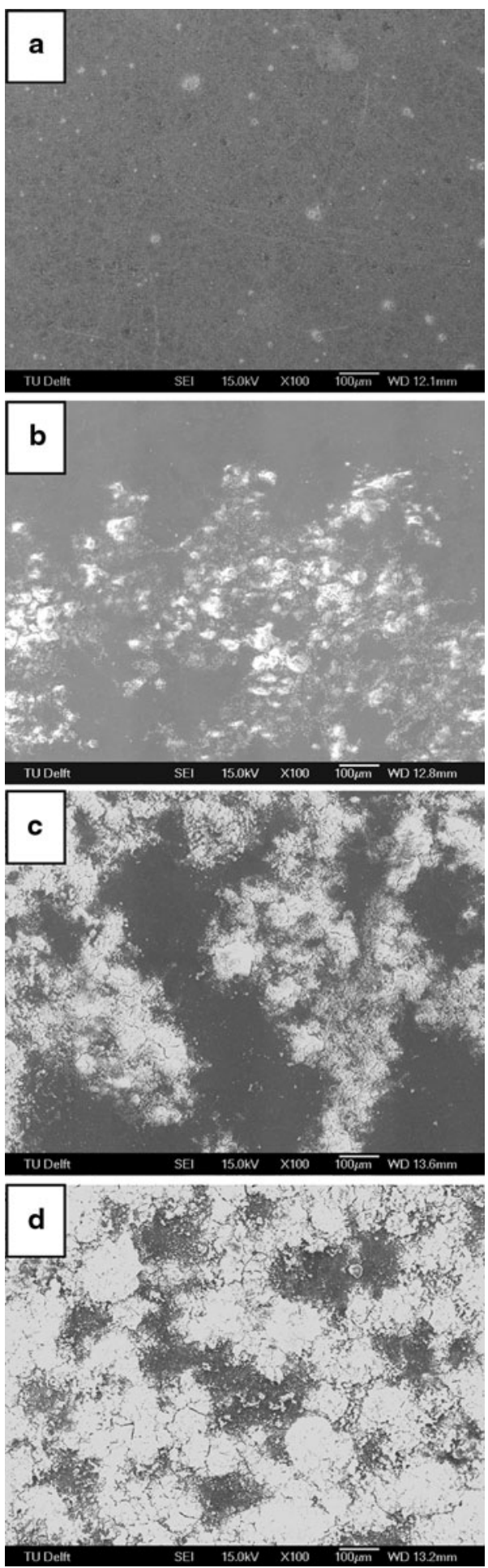

Fig. 5 SEM micrographs of the ZK30 alloy (a) and the composites with $3.4 \%$ (b), $6.9 \%$ (c) and $14.3 \%$ (d) BG particles by volume after immersion in E-MEM for $24 \mathrm{~h}$

metallic magnesium may be as follows [21]: an ionic exchange between $\mathrm{Mg}^{2+}$ from the substrate and $\mathrm{H}^{+}$from the soaking medium takes place, leading to an increase in $\mathrm{pH}$; higher $\mathrm{pH}$ values increase the supersaturation degree 


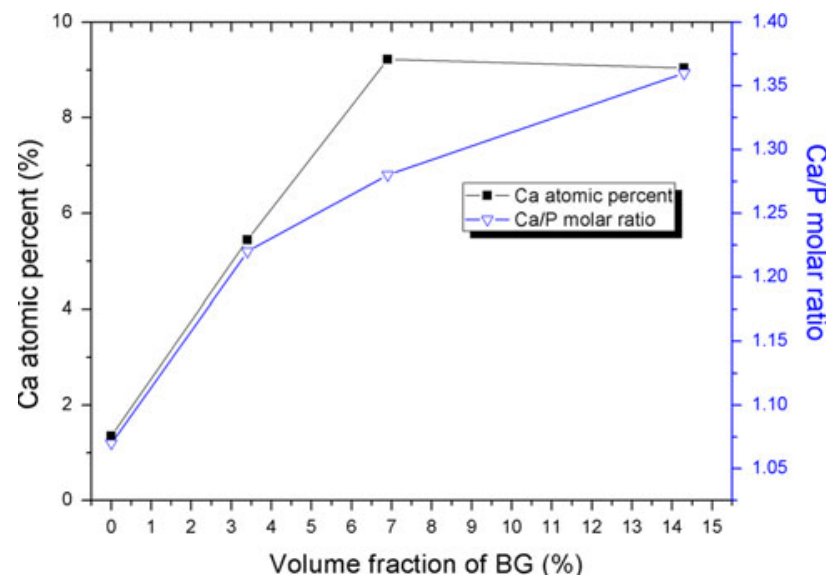

Fig. $6 \mathrm{Ca}$ atomic percents and $\mathrm{Ca} / \mathrm{P}$ molar ratios of the surface layer formed on the composite samples with different volume fractions of BG particles after immersion in E-MEM for $24 \mathrm{~h}$

of the cell culture medium with respect to apatite. The result is the nucleation and growth of a Ca-, $\mathrm{P}$ - and $\mathrm{Mg}$-rich ceramic layer on the magnesium substrate. With the addition of BG particles, apart from the supersaturation caused by the elevated $\mathrm{pH}$ environment, the apatite layer formation is accelerated due to the release of $\mathrm{Ca}^{2+}$ from the partial dissolution of BG particles. The silicon dissolved from the BG particles surface may act as a nucleating agent [18], thereby accelerating the formation of the apatite layer which can significantly improve the surface biocompatibility of the material $[8,9]$. In combination with the consideration on the compressive strengths of the composites (Fig. 2), the ZK30-BG composite with $6.9 \%$ BG by volume showed the best balanced properties. Further research on the biocompatibility and bioactivity of the composites and other aspects relevant to the biomedical application will be carried out to optimize both material design and processing further.

\section{Conclusions}

For the first time, $\mathrm{Mg}$-based metal matrix composites with bioactive glass as reinforcing particles were fabricated by the semi-solid high pressure casting method. BG particles were homogeneously distributed in the composites. The materials showed slightly porous structures and had compromised mechanical strengths. Nevertheless, BG particles survived the casting process with their chemical composition intact. Accelerated formation of an apatite layer on the composite surface occurred, indicating an improved surface biocompatibility of the material. These results demonstrated the feasibility of improving the surface biocompatibility of Mg-based implant materials by adding bioactive particles. Further research on material-cell interactions would be of great value to show the potential of the composites as biodegradable, bioactive orthopaedic materials.

Acknowledgments The author would like to thank Prof. Jiang Chang of the Biomaterials and Tissue Engineering Research Centre, Shanghai Institute of Ceramics, Chinese Academy of Sciences, China, and Dr. Haim Rosenson of the Israel Institute of Metals, Technion R\&D Foundation, Israel, for their contributions to this research.

Open Access This article is distributed under the terms of the Creative Commons Attribution Noncommercial License which permits any noncommercial use, distribution, and reproduction in any medium, provided the original author(s) and source are credited.

\section{References}

1. Staiger MP, Pietak AM, Huadmai J, Dias G. Magnesium and its alloys as orthopaedic biomaterials: a review. Biomaterials. 2006; 27:1728-34.

2. Zeng R, Dietzel W, Witte F, Hort N, Blawert C. Progress and challenge for magnesium alloys as biomaterials. Adv Eng Mater. 2008;10:B3-14.

3. Peng M, Huang Y, Zhou L, Hort N, Kainer KU. Preparation and properties of high purity Mg-Y biomaterials. Biomaterials. 2010; 31:398-403.

4. Gray-Munro JE, Seguin C, Strong M. Influence of surface modification on the in vitro corrosion rate of magnesium alloy AZ31. J Biomed Mater Res. 2009;91A:221-30.

5. Xu L, Yu G, Zhang E, Pan F, Yang K. In vivo corrosion behavior of $\mathrm{Mg}-\mathrm{Mn}-\mathrm{Zn}$ alloy for bone implant applications. J Biomed Mater Res. 2007;83A:703-11.

6. Zhang S, Zhang X, Zhao C, Li J, Xie C, Tao H, Yang Y, He Y, Jiang Y, Bian Y. Research on an Mg-Zn alloy as a degradable biomaterial. Acta Biomater. 2010;6:626-40.

7. Zhang $\mathrm{E}, \mathrm{Xu} \mathrm{L}$, Yang K. Investigation on new biomedical degradable magnesium alloys. In: Proc. of the 2006 Beijing International Materials Week, Beijing, China; June 25-30, 2006. p. 317.

8. Xu L, Pan F, Yu G, Yang L, Zhang E, Yang K. In vitro and in vivo evaluation of the surface bioactivity of a calcium phosphate coated magnesium alloy. Biomaterials. 2009;30:1512-23.

9. Ye X, et al. In vitro corrosion resistance and cytocompatibility of nano-hydroxyapatite reinforcement $\mathrm{Mg}-\mathrm{Zn}-\mathrm{Zr}$ composites. J Mater Sci Mater Med. 2010;21:1321-8.

10. Ning $C$, Zhou $Y$. In vitro bioactivity of a biocomposite fabricated from HA and Ti powder by powder metallurgy method. Biomaterials. 2002;23:2909-15.

11. Witte F, Feyerabend F, Maier P, Fischer J, Störmer M, Blawert C, Dietzel W, Hort N. Biodegradable magnesium-hydroxyapatite metal matrix composites. Biomaterials. 2007;28:2163-74.

12. So K, Fujibayashi S, Neo M, Anan Y, Ogawa T, Kokubo T, Nakamura T. Accelerated degradation and improved bonebonding ability of hydroxyapatite ceramics by the addition of glass. Biomaterials. 2006;27:4738-44.

13. Huan Z, Leeflang MA, Zhou J, Fratila-Apachitei, Duszczyk J. In vitro degradation behaviour and cytocompatibility of $\mathrm{Mg}-\mathrm{Zn}-\mathrm{Zr}$ alloys. J Mater Sci Mater Med. 2010;21:2623-35.

14. Yamamoto A, Hiromoto S. Effect of inorganic salts, amino acids and proteins on the degradation of pure magnesium in vitro. Mater Sci Eng C. 2009;29:1559-68. 
15. Kokubo T, Takadama H. How useful is SBF in predicting in vivo bone bioactivity? Biomaterials. 2006;27:2907-15.

16. Hashim J, Looney L, Hashmi MSJ. Metal matrix composites: production by the stir casting method. J Mater Process Technol. 1999;92-93:1-7.

17. Akao M. Mechanical properties of sintered hydroxyapatite for prosthetic applications. J Mater Sci. 1981;16:809-12.

18. Best SM, Porter AE, Thian ES, Huang J. Bioceramic, past, present and for the future. J Eur Ceram Soc. 2008;28:1319-27.

19. Santos JD, Jha LJ, Monteiro FJ. In vitro calcium phosphate formation on $\mathrm{SiO}_{2}-\mathrm{Na}_{2} \mathrm{O}-\mathrm{CaO}-\mathrm{P}_{2} \mathrm{O}$ glass reinforced hydroxyapatite composite: a study by XPS analysis. J Mater Sci Mater Med. 1996;7:181-5.

20. Andersson $\mathrm{OH}$, Kangasniemi I. Calcium phosphate formation at the surface of bioactive glass in vitro. J Biomed Mater Res. 1991;25:1019-30.

21. Cortes DA, Lopez HY, Mantovani D. Spontaneous and biomimetic apatite formation on pure magnesium. Mater Sci Forum. 2007;539-543:589-94. 